\title{
Theoretical Research of the Breakdown Mechanism of the Pseudospark Discharge in the Field of Pulsed Power Engineering
}

\author{
Xiaowei. $\mathrm{Gu}^{1,2}$ \\ ${ }^{1}$ School of Information Science and Technology, Zhejiang Sci-Tech University \\ Hangzhou 310018,China \\ ${ }^{2}$ College of electrical engineering, Zhejiang University, \\ Hangzhou 310027, China \\ e-mail: gxw@zstu.edu.cn
}

\begin{abstract}
Pulsed power technology is the key technologies of the future of national defense, while the intense electron beam source development is the high-power microwave bottlenecks. Based on previous experimental, a pseudospark discharge is a viable possibility in this respect, a small-scaled and intense PS electron beam source was conceived to drive a high energy microwave tubes. The electrons emission is the first step of Pseudospark discharge plasmas breakdown, due to high-field emission. Based on filed emission mechanism, a cathode spot heat conduction model of Pseudospark discharge is set up to deduce the microscopic transport characteristics of initial plasmas by mathematics model building method and thermodynamics motion equations. The microscopic transport characteristics of initial plasmas are embodied mainly in the breakdown phase of discharge. So, the breakdown time(trigger delay) of Pseudospark is calculated from the heat conduction model. This research of plasmas discharge microscopic transport characteristics in order to lay the theoretical foundation for the optimize and improve Pseudospark device design.
\end{abstract}

Keywords-Analytical theory; Breakdown mechanism; Pseudospark discharge; Field emission; Superdense glow discharge

\section{INTRODUCTION}

Discovered 1970s, The pseudospark discharge is recognized as unique type of discharge which is capable of producing electron beams with highest combined current density and brightness of any known type of electron source. pseudospark discharge continues to be studied with regard to its discharge physics mechanism, its applications as a high power pulsed power technology and as a high quality electron beam source ${ }^{[1-5]}$. A pseudospark is an axially symmetric, self-sustained, transient, low pressure (typically 50-500 mTorr) gas discharge in a hollow cathode/planar anode configuration, which operates on the left-hand side of the hollowcathode analog to the Paschen curve. This discharge is characterized by a very rapid breakdown phase, during which high-density particle beams can be extracted and rapid increasing rate of current can be achieved. Based on these, it has been widely applied in plasma processing (ion-etching, thin film deposition, surface processing), gas laser, electron gun, microwave generation, electron beam melting, welding, surface treatment, plasma chemistry, radiation technologies, laser pumping, light source and spectrum analysis. The breakdown phase of Pseudospark discharges is very essential in the whole hollow cathode discharge procedure, because a potentially useful property of this type of discharge is the formation of an electron beam during the breakdown process. At present, the many research people used experiment tools to study the discharge breakdown formation process (ultra fast shutter camera, probe and so on). In this condition, the plasma is generated in the closure cavity and the electron is extracted from some boundary of the plasma and accelerated to form the Ebeam. Physically, the electron is emitted from the flashover plasma on the surface of cathode, although the plasma density is significantly higher than that of any material cathode, the damage owing to high-energy ion impacts will become the least since the resultant cathode is essentially a plasma. Pseudospark discharge offers the electron beam of high current density, high brightness and narrow beam diameter. Our focus is to develop high energy, intense current, annular electron beams which are very attractive as an electron beam source for high pulse power.

This paper is outlined as follows: in seciton2, pseudospark discharge apparatus is briefly. In section3, Analytical theory model is briefly described, including the mathematics model building method and thermodynamics motion equations considered. Then a short summary is given in section4.

\section{PSEUDOSPARK DISCHARGE APPARATUS}

A new multi-gap Pseudospark discharge experiment cavity has been carried out to prove the concept of the generation of a narrow electron beam as shown in Fig .1 The experimental setup has already been described 
elsewhere $^{[6-28]}$. We will only briefly outline it here. The basic component of such a device is its Pseudospark discharge chamber. It's outward appearance, which consisted of a $30 \mathrm{~mm}$ diameter, $28 \mathrm{~mm}$ length cylindrical hollow cathode cavity, and a planar anode, eighteen intermediate electrodes of $5 \mathrm{~mm}$ thickness and Perspex insulators washers stacked alternately. The anode-cathode gap distance is $20 \mathrm{~cm}$, the last gap connected to the anode in order to prevent possible local flashovers and long-path discharges outside of the discharge chamber during the application of applied pulse voltage over it, the discharge chamber was installed in the high vacuum by a mechanical pump, then the automatically controlling pressure system dynamically and steadily adjusts the operating pressure at the desired value, which can be continually adjusted in the range of 5-200 $\mathrm{Pa}$ by controlling a piezoelectric valve in the gas feeding passage between the low pressure chamber and the gas source. Therefore, the entire device includes a Marx generator, a Pseudospark discharge chamber, a controlling system of the gas pressure and beam drift tube.The diagnostic system of the generated electron beam includes a calibrated Rogowski coil and high voltage oscilloscope. The Rogowski coil was embedded in the anode flange to measure the ejected electron beam current and its pulse duration. The cathode side of the chamber was charged up through a charging resistor and the charging voltage was measured by a high-voltage probe. The beam damage shapes are measured with a copper foil which was placed at the exit.

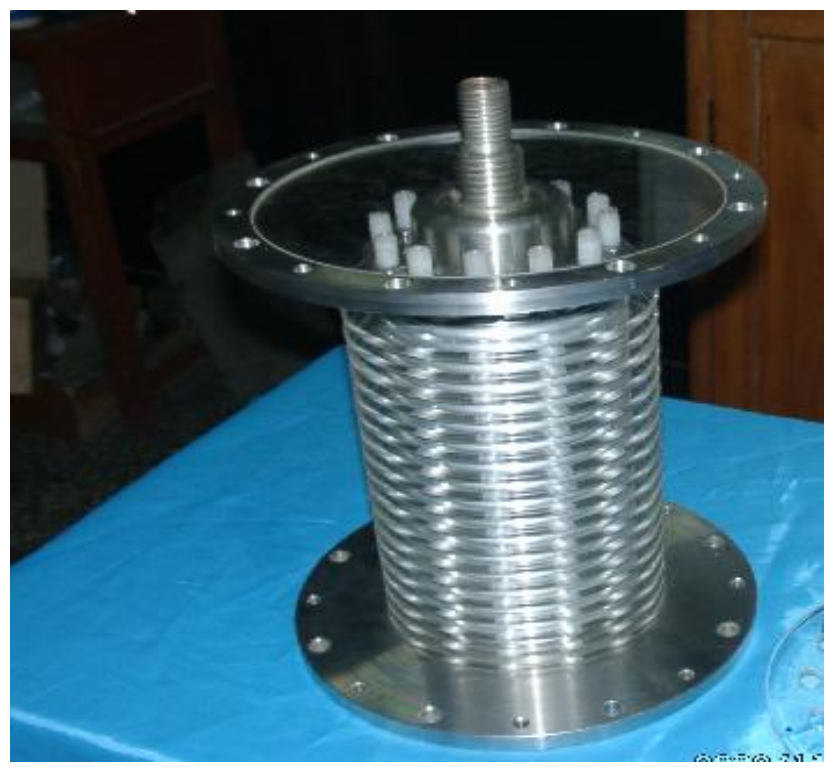

Figure 1. Developed Multigap pseudospark discharge cavity

However, it is quite difficult to know the detailed pseudospark discharge process in the hollow cathode cavity in the experiments. Particularly few investigations were reported on the physical mechanisms for this type of gas discharge breakdown process. Nevertheless these researches that has still not been fully explored is that of pseudospark discharge.

\section{ANALYTICAL THEORY OF BREAKDOWN MECHANISM}

Experimental research and theoretical analysis of the gas discharge are important in understanding the law of gas discharge ${ }^{[29-30]}$, making use of electrical characteristic of gaseous dielectric, developing new type gas switch. Researchers have done lots of researching work in breakdown phenomena of gas discharge and gained great achievement but there is no an ideal model to describe it. because the process of gas discharge concerns lots of affecting factors. The field emission is considered very important, the electron current density emitted from the cathode surface due to the field emission $j_{1}$ is described by the modified Fowler-Nordheim formula for the cold cathode

$$
j_{1}=\frac{A E^{2}}{\varphi t^{2}(y)} f_{T} \exp \left[-\frac{C \varphi^{3 / 2} v(t)}{E}\right]
$$

where $j_{1}$ in $\mathrm{A} / \mathrm{cm} 2, y=B E^{1 / 2} / \phi$ is a function of the cathode field strength $E$ (in $\mathrm{V} / \mathrm{cm}$ ) and work function $\phi$ (in $\mathrm{eV}$ ) of cathode material, $t(y)$ and $v(y)$ are functions related to the elliptic function, $f_{T}=z / \sin (z), z=D T \phi^{1 / 2} / E$ $A=1.54 \times 10^{-6}, B=3.79 \times 10^{-4}, C=6.83 \times 10^{7}, D=2.77 \times 10^{4}$ Numerical calculation for (1) shows that only when the electric field must be larger than $3 \times 10^{7} \mathrm{~V} / \mathrm{cm}$. does $j_{1}$ have significant growth.

Field-enhanced thermionic emission appears in the middle of the pseudospark discharge phase due to energy deposition and heating effects. An initial cathode is cold because additional heating effects and energy deposition can be ignored in the early part of pseudospark discharge process. Joule heating, which is caused due to emitting electrons from inside the cathode under the influence of electrical field. The resistive heating and the ion impacting make the cold cathode surface become hotter with the time. The current density can be described by the Richardson-Schottky(RS) formula(2)

$$
j_{2}=\frac{4 \pi m_{e}(k T)^{2}}{h^{3}} \exp \left[-\frac{\varphi-\sqrt{e^{3} E}}{k T}\right]
$$

Follow the above formula, it can be seen when E, is lower than $5 \times 10^{6} \mathrm{~V} / \mathrm{cm}$, the cathode temperature must be over $3300 \mathrm{~K}$. Note that field strengths at the tips of micropoints (in the discharge cathode) can reach, even are higher than, $1 \times 10^{7} \mathrm{~V} / \mathrm{cm}$.

Assuming that the ion and electron bombardment is the transiently heat source which heats the the cathode surface. Mathematics model building method and thermodynamics motion equations as a function of time with a constant power flow density $F_{0}$ is given as follows(3)

$$
T(0, t)=T_{0}+\left(2 F_{0} / K\right) \sqrt{k t / \pi}, x=0
$$

where $K, \rho, C$ and $k=K / \rho C$ are the thermal conductivity, mass density, specific heat, and diffusivity 
of the cathode material, respectively, and $\mathrm{x}$ is the heatpenetrating depth into the cathode surface. Follow the above the formula, we can get the heated cathode temperature, to produce the observed current density of breakdown process of pseudospark discharge.

Naturally, there have clear bombardment traces on the copper deeply due to high energy particle in the Fig .2 Therefore, a clear distinction between this kind of pulsed intense electron beam and the conventional electron beam sources based on thermoionic or field emission cathodes must be made.

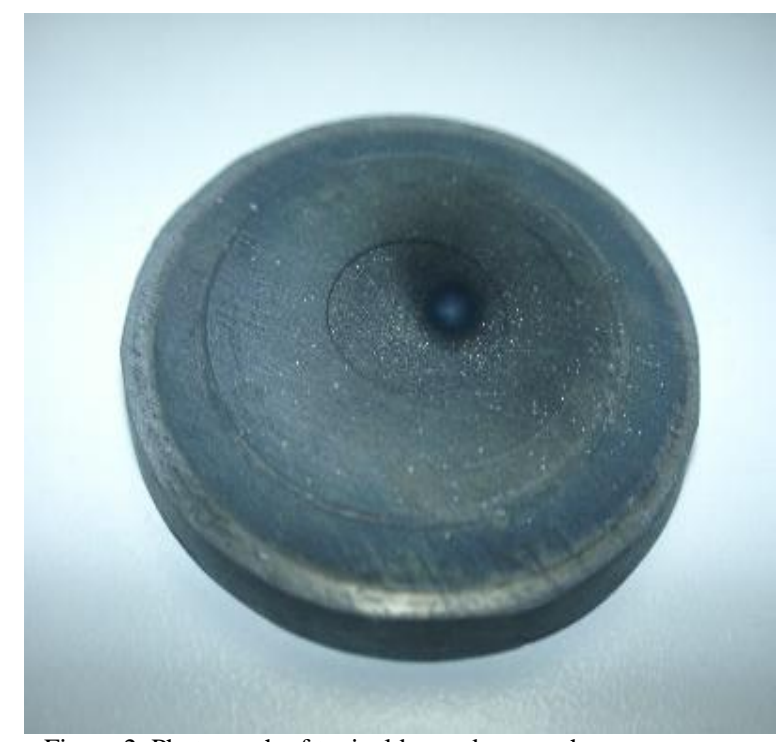

Figure 2. Photograph of typical beam damage shape on copper

\section{SUMMARY}

We successfully designed the analytical theory of the Pseudospark discharge breakdown mechanism. After triggering, the plasma in the pseudospark is formed and is terminated by plasma-cathode wall breakdown and the formation of cathode spots. This results in plasma density increase and the onset of high current phase. a cathode spot heat conduction model of Pseudospark discharge is set up to deduce the microscopic transport characteristics of initial plasmas by mathematics model building method and thermodynamics motion equations. New mechanisms are proposed for later phases in the development of the pseudospark discharge. This research of plasmas discharge microscopic transport characteristics might bring a new insight on the physical model of this complex breakdown transient discharge.

\section{ACKNOWEDGEMENTS}

This work was financially supported by the National Natural Science Foundation of China(11347125), Zhejiang Provincial Natural Science Foundation of China (Y14E070029), Zhejiang Qianjiang Talent Project (2013R10064) ,China Postdoctoral Science Foundation (2014M551735), Science Foundation of Zhejiang SciTech University (1104826-Y).

\section{REFERENCES}

[1].H. Yin, W. He, A.W. Cross, A.D.R. Phelps. "Singlegap pseudospark discharge experiments," Journal of Applied Physcis, vol.90, No.7, Oct. 2001,pp.3212-3218. [2].H. Yin, A. W. Cross, W. He, A.D.R.Phelps,K.Ronald, D.Bowes and C.W.Robertson. "Millimeter Wave Generation from a Pseudospark-sourced electron beam," Physics of Plasmas, vol.16, No.6, Jun. 2009,pp. 063105,.. [3].H.Yin, D.Bowes,W.He, A.W.Cross, A.D.R. Phelps, K. Ronald, D. Li, and X. Chen. "Pseudospark-sourced Micro-sized electron beams for high frequency klystron applications." Terahertz science and technology, vol.4, No.3, Nov, 2011,pp.71-75,

[4].Niraj Kumar, U. N. Pal, D. K. Verma J. Prajapati,

M. Kumar, B. L. Meena, M. S. Tyagi, V. Srivastava. "Experimental analysis of pseudospark soured electron beam," J Infrared Milli Terahz Waves, vol. 32, Dec.2011, pp.1415-1423,

[5].Jitendra Prajapati, U.N.Pal, Niraj Kumar, D.K.Verma, Ram Prakash, V.Srivastava. "comparative simulation studies of plasma cathode electron(PCE) gun," Journal of Physics: conference Series,vol.365, May.2012, pp.012051.

[6].N.Savoulides, S.A.Jacobson, Li Hanqing , Ho Linhvu, R.Khanna, Teo Chiang-Juay, J.M. Protz, Wang Li, D.Ward, M.A.Schmidt, A.H.Epstein," Fabrication and Testing of a High-Speed Microscale Turbocharger", Journal of Microelectromechanical Systems; Oct. 2008; Vol. 17, Issue 5; pp. 1270-1282.

[7].L. Jiang, G. Pandraud, P. J. French, S. Spearing, M. Kraft,"A Novel Method for Nanoprecision Alignment in Wafer Bonding Applications", Journal of Micromechanics and Microengineering; June 2007; Vol. 17,issue 7, pp. S61-S67.

[8].H. Yin, A. W. Cross, W. He, A. D. R. Phelps, K. Ronald, D. Bowes, and C. W. Robertson, "Millimeter Wave Generation from a Pseudosparksourced electron beam", Physical of Plasmas, Vol.16, No. 6, 063105 , (2009).

[9]1. D. M. Goebel, J. M. Butler, R. W. Schumacher, J. Santoru, and R. L. Eisenhart, "High- power Microwave source based on an unmagnetized Backward-wave Oscillator". IEEE Trans. Plasma Sci. Vol.22, 1994,pp. 547-553.

[10]H. Yin, A. W. Cross, W. He, A. D. R. Rhelps, and K. Ronald, "Pseudospark experiments: Cherenkov interaction and electron beam post-acceleration". IEEE Trans. Plasma Sci. Vol.32, 2004,pp. 233-239.

[11]J. B. Zhu, Z. J. Wang, L. F. Zhang, and M. C. Wang, "An improved pulse-line Accelerator driven intense current-density and high-brightness pseudospark electron beam", IEEE Trans. Plasma Sci, Vol.24, 1996,pp.161-164.

[12]E. Dewald, K. Frank, D. H. H. Hoffmann, R. Stark, M. Ganciu, B. N. Mandache, M. G. Nistor, A. M.Pointu, and I.I Popescu, "Pulsed intense electron beams generated in transient hollow cathode discharges: 
fundamentals and applications". IEEE Trans. Plasma Sci. Vol.2, 1997,pp.272-278.

[13].A. W. Cross, Y. Yin, D. Bowes, W. He, K. Ronald and A.D. R. Phelps, "Pseudospark-sourced electron beam for millimetre wave and terahertz generation", New Developments in Nonlinear Plasma Physics, Vol.1188, 2009, pp.380-390.

[14].A.W. Cross, H. Yin, W. He, K. Ronald, A.D.R. Phelps, L.C. Pitchford, "Generation and application of pseudospark-sourced electron beams", Journal of Physical. D: Apply. Physic., Vol.40, Issue.7, March.2007, pp.1953-1956.

[15].N. Kumar, U.N.Pal, D.K.Verma, J.Prajapati, M.

Kumar, B. L. Meena, M. S. Tyagi and V.Srivastava,"Experimental Analysis of Pseudospark Sourced Electron Beam" ,Journal of Infrared, Millimeter and Terahertz Waves,Vol.32, Jan.2011,pp:1415-1423.

[16].N.Kumar, N.Pareek, U.Narayanpal, D.K.Verma, J.Prajapati, M.Kumar, B.L.Meena and R.Prakash."Performance evaluation of self-breakdownbased single-gap plasma cathode electron gun", PRAMANA-Journal of Physics, Vol.82,No.6.June 2014, pp.1075-1084.

[17]H.Reather. Electron Avalanches and Breakdown in Gases[M].UK, London: Butterworths, 1964.

[18]T.H.Martin, A.H.Guenther and M.Kristiansen. J.C. Martin on Pulsed Power[M].New York and London: plenum press, 1996.

[19]A.N.Tagarlov, I.M.Rutkevich. Ionization waves in electrical breakdown of gases [M] Springer-Verlag, USA, 1994

[20]P.Choi, H.Chuaqui, M.Favre, and V. Colas, "Breakdown formation in a transient hollow cathode discharge-A statistical study," IEEE Trans Plasma Sci Vol.23,No.3, 1995,pp.221-228 .

[21]M.Favre, P.Choi, H. Chuqui, R. Aliaga, Y. Kaufman, J. Moreno, E. Wyndham, and M. Zambra, "Hollow cathode effects in charge development processes in transient hollow cathode discharges," IEEE Trans Plasma Sci Vol.23, Vol.3, 1995,pp. 212-220.

[22]J. Moreno, M. Zambra, and F. M. Further,"Statistical studies of ionization growth and breakdown formation mechanisms in the final breakdown phase of a transient hollow cathode discharge," IEEE Trans Plasma Sci Vol.30, No.1, 2002,pp. 417-422.

[23]K. Ramaswamy, W. W. Destler, and J. Rodgers, “A high-Voltage triggered pseudospark discharge experiment,” J Appl Phys Vol.80,No.9, 1996,pp.48874895

[24]P. Choi, H. Chuaqui, J. Lunney, R. Reichle, A. J. Davies, and K. Mittag, "Plasma formation in a pseudospark discharge," IEEE Trans Plasma Sci Vol.17,No.5,1989, pp.770-774.

[25]X. L. Jiang, "Field escalation effect in the pulsed ion beam sources based on the pseudospark discharge," Rev Sci Instr Vol.63,No.4, 1992, pp. 2420-2421.

[26]J.P.Boeuf and L.C.Pitchford, "Pseudospark discharges via computer simulation," IEEE Trans Plasma Sci Vol.19, No.2, 1991, pp.286-296.

[27]Z. Donko and I. G. Mikellides, "Hybrid model of a rectangular hollow cathode discharge," Phys Rev Vol.57 No.6, 1998, pp.7126-7137.

[28]I. G. Mikellides, I. Katz, I. Katz, D. M. Goebel, and J. E. Polk, "Hollow cathode theory and experiment.II. A two-dimensional theoretical model of the emitter region,” J Appl Phys Vol.98,No.11, 2005, pp.1-14.

[29]C. K. Birdsall and A. B. Langdon,Plasma physics via computer simulation, McGraw-Hill, New York,1985, pp. 389-392.

[30]S. O. Cetiner, P. Stoltz, P. Messmer, and J. L. Cambier,"Dependence of electron peak current on hollow cathode dimensions and seed electron energy in a pseudospark discharge,'J Appl Phys Vol.103, 2008, pp. 023304. 